\title{
Apego e posse em psicoterapias psicodinâmicas
}

\author{
Sebastião Elyseu Júnior \\ Elisa Medici Pizão Yoshida \\ Pontifícia Universidade Católica de Campinas
}

\begin{abstract}
RESUMO
O objetivo deste artigo foi o de demonstrar como padrões de apego e de posse aparecem na comunicação transferencial de pacientes em psicoterapias psicodinâmicas e como podem orientar as intervenções do terapeuta. Propõe-se que a posse seja compreendida, de forma complementar à teoria do apego de John Bowlby. Apresentam-se as formulações teóricas do apego e da posse, juntamente com limites e especificidades de cada construto. Em relação especificamente à experiência psicológica da posse, propõe-se que ela pode ser relacionada a diferentes figuras de posse tais como, pessoas, animais e/ou coisas. É ainda proposto, que ela se expressa de acordo com padrões recorrentes de posse psicológica designados de acordo com os sentimentos predominantes associados. Com base em experiência clínica, foram identificados os seguintes padrões: de posse segura, de posse ansiosa, de posse ciumenta e de posse reativa. Trechos de sessões psicoterápicas são apresentados para ilustrar como estes conceitos podem ser manejados pelo terapeuta em suas intervenções, assim como possíveis desenvolvimentos no processo de elaboração do paciente.
\end{abstract}

Palavras-chave: transferência; padrões de apego; posse psicológica.

\section{ABSTRACT}

\section{Attachment and ownership in psychodynamic psychotherapies}

The objective of this article has been to demonstrate how patterns of attachment and of ownership appear in the transferential communication of patients in psychodynamic psychotherapies and how they can guide the therapist's interventions. It is proposed that ownership should be understood complementarily to John Bowlby's theory of attachment. The theoretical rationales of attachment and ownership are presented along with some limits and specificities of each construct. Regarding specifically the ownership experience, it is proposed that it can be related to different ownership figures such as people, pets and/or things. It is also proposed that the ownership experience is expressed according to recurrent psychological patterns, designed according to the associated predominant feelings. Based on clinical experience, the following patterns were identified: pattern of secure ownership, of anxious ownership, of jealous ownership and of reactive ownership. Excerpts from different patients' psychotherapeutic sessions are offered to illustrate how these concepts can be handled by a therapist in his or her interventions, and also to exemplify possible developments in the patient's ongoing process of working through his conflicts.

Keywords: transference; patterns of attachment; psychological ownership.

O objetivo das psicoterapias psicodinâmicas é o de levar o paciente a resolver os principais conflitos de natureza intra e interpessoal, através da identificação do padrão relacional que se atualiza na transferência (Yoshida \& Rocha, 2007). Para tanto, o terapeuta deve ajudá-lo a identificar o sentimento (ou impulso) predominante na situação conflituosa, a ansiedade vivenciada, assim como os mecanismos de defesa mais evidentes. Esses três pontos configuram o chamado "triângulo de conflito", que deve ser examinado no contexto dos episódios relacionais que envolvem, além do terapeuta, outras pessoas do presente e do passado do paciente ("triângulo de pessoas”) (Malan, 1979/1983).

Dentre os padrões que se manifestam na transferência destacam-se os de apego (Aisnworth, Blehar, Waters \& Wall, 1978; Main \& Solomon, 1990, citado por Fonagy, 1999) e os de posse (Elyseu Jr., 1998, 2006), devido ao papel que desempenham na qualidade dos relacionamentos interpessoais. E nesse sentido, o presente trabalho tem como objetivo demonstrar como esses padrões aparecem na comunicação trans- 
ferencial de pacientes em psicoterapias psicodinâmicas e como eles podem orientar as intervenções do terapeuta.

Inicialmente são apresentadas as formulações teóricas de apego e de posse para demarcar os limites e especificidades de cada constructo, e em seguida algumas ilustrações com base em fragmentos de casos clínicos, ajudam a contemplar os objetivos do trabalho.

\section{Teoria do Apego}

Ao apontar para os efeitos da separação da mãe nos primeiros anos de infância sobre o desenvolvimento da personalidade, Bowlby (1969) apoiou-se nas observações feitas por James Robertson, de numerosas crianças (a maioria no segundo e terceiro anos de vida), durante e depois de uma temporada de semanas ou meses fora de casa. Impressionara-o, profundamente, a extensão e a duração dos distúrbios, mesmo depois do regresso delas ao lar. Na época, entretanto, não houve concordância de outros pesquisadores sobre a importância e o significado da perda da figura materna para o desenvolvimento psicopatológico, que Bowlby (1969) acreditava constituir a variável dominante naquele processo.

As reações mais significativas observadas nas crianças de mais de seis meses separadas de suas mães eram de protesto, de desesperança e de desapego. E, quando elas voltavam para casa, as reações mais evidentes eram ou de intenso agarramento à mãe, o que se mantinha por semanas, meses ou anos, ou de rejeição, temporária ou permanente, a ela. As conclusões gerais de estudos mais aprofundados sobre a saúde mental de crianças sem lar, que confirmam e ampliam os dados obtidos por Robertson, são resumidamente: que a perda ou privação da figura materna por si só ou combinada com outras variáveis pode gerar reações e processos psicopatológicos e que essas reações e processos são os mesmos que estão ativos em adolescentes e adultos ainda perturbados por separações sofridas nos primeiros anos de vida (Bowlby, 1965, 1969). Era o início do que se tornaria a Teoria do Apego.

Trabalhos dos mais significativos para essa teoria foram os de Mary D. S. Ainsworth, que após refletir sobre as suas observações de bebês gandas pôde estabelecer o conceito de base segura (Ainsworth, 1963). Esses bebês usavam a sua mãe como ponto de partida para as suas explorações, isto é, faziam pequenas incursões exploratórias no ambiente e voltavam, de quando em quando, a ela. As crianças amedrontadas (inseguras) não faziam isso, de sorte que o comporta- mento exploratório passou a ser considerado como uma dimensão capaz de discriminá-las quanto ao tipo de vinculação (padrão de apego) que mantinham com a mãe.

Um outro trabalho, realizado com 83 crianças de 12 meses e suas mães, permitiu a Aisnworth e cols. (1978) discriminar melhor os padrões de apego da criança à sua mãe (figura de apego), em virtude da interação entre elas, e considerar a segurança do apego como a dimensão de maior utilidade na sua compreensão. Um padrão de apego é, pois, a forma pela qual o comportamento de apego se organiza em virtude das experiências com as figuras de apego durante a infância e a adolescência; e, uma figura de apego ( $f d a)$ é aquela mais capaz que o indivíduo para fazer frente a uma situação adversa e à qual ele recorre por meio do comportamento de apego (Bowlby, 1969).

A criança que tem uma base segura tende a desenvolver um padrão de apego seguro, caracterizado segundo Ainsworth e cols. (1978) por ela ser capaz de fazer explorações numa situação estranha quando a mãe está por perto, por não se afligir com a chegada de uma pessoa estranha, por mostrar que está ciente do paradeiro da mãe, e por acolhê-la alegremente quando ela retorna, buscando o seu colo ou mantendose junto dela. Esse padrão é considerado saudável psicologicamente o que não acontece com os seguintes.

A criança que tem uma base insegura tende a desenvolver um padrão de apego inseguro, caracterizado pela ausência de explorações no ambiente, mesmo com a mãe presente, por desmoronar-se no desamparo e na desorientação na ausência da mãe, por mostrar-se alarmada com a chegada de um estranho, e por não acolher alegremente a mãe quando essa retorna. Pelo tipo de resposta que as crianças manifestavam em relação à mãe no seu retorno esse padrão de apego foi subdividido em: resistente, quando a criança mostrava forte ansiedade e raiva pela separação e dificuldade em recompor-se mesmo quando os cuidadores tentavam acalmá-la e reconfortá-la, e em evitante, quando a criança tendia a evitar a proximidade à mãe não a preferindo mais do que a um estranho. A quarta categoria, isto é, o padrão de apego desorganizado/desorientado, segundo Main e Solomon (1990, citado por Fonagy, 1999), caracteriza-se pelo imobilismo da criança, por pancadas que ela dá com as mãos ou com a cabeça, aparentemente sem um objetivo definido, causando a impressão de desorganização e desorientação. Além disso deseja evadir-se da situação mesmo com os cuidadores presentes. Supõe-se diante disso 
que para a criança o cuidador pode ser fonte tanto de reasseguramento, quanto de temor.

Bowlby (1973) lembra que, depois de ter identificado em 1952, junto com Robertson, as reações de crianças à separação de suas mães em ambientes institucionais como as de protesto, de desespero e de desapego, ele mesmo formulou a tese de que elas são fases de um único processo no qual o protesto expressa a ansiedade de separação, o desespero revela a tristeza e o luto pela perda da esperança em recuperar a mãe e o desapego expressa uma defesa contra o sofrimento a uma nova separação (Bowlby, 1960). Entende-se que no desapego há uma desativação do comportamento de apego da criança; porém, isso pode ser revertido caso não se estruture em um padrão fixo, condição essa psicopatológica. Esses padrões são estruturados de acordo com o tipo de experiência que o indivíduo tem com as suas figuras de apego, e constituem aspectos integrantes da personalidade normal ou patológica.

Cabe ainda ressaltar que Bowlby (1988/1989) não só ficou grato a Mary Ainsworth pelo seu conceito de base segura, mas também passou a considerá-lo crucial para compreender como uma pessoa se desenvolve e funciona durante toda a sua vida de maneira emocionalmente estável. Tal importância decorre do fato de que sem uma figura maternal protetora o filho não sobrevive. A proteção é exercida pela figura de apego por meio de um comportamento instintivo de cuidar, identificado e reconhecido tanto na espécie humana como em outras espécies animais.

O filho, por seu lado, complementa o comportamento de cuidar por meio de um comportamento instintivo de apego, caracterizado pela busca e/ou manutenção de proximidade ou contato a essa figura para ser cuidado, especialmente protegido por ela - e não devendo, portanto, ser confundido com qualquer outro sentido de comportamento de busca ou de proximidade a ela. O comportamento de apego é, conceitualmente, o resultado de um sistema de regulação homeostática de segurança, que concorre para a proteção do próprio indivíduo.

A propósito, Bowlby (1990) afirma que no relacionamento interpessoal há mais do que um programa diádico partilhado de apego-cuidado, e que Bretherton (1980) estava correta quando disse que ele, ao definir o comportamento de apego, tinha em mente o resultado de um sistema comportamental de regulação de segurança. As atividades desse sistema tendem a diminuir o risco de o indivíduo dar-se mal e levam-no a sentir um alívio de ansiedade e um aumento do sentimento de segurança. Nesse sentido, ele sugeriu que o comportamento de apego é uma resposta instintiva contra os perigos do meio ambiente de adaptabilidade evolutiva da espécie, entre os quais o maior é a ação de predadores.

\section{Teoria da Posse}

Apesar da excelência da Teoria do Apego existem dois fatos fundamentais a considerar: a ansiedade não é uma resposta restrita à frustração do comportamento de apego, mas a qualquer evento que coloque em risco a estabilidade do indivíduo, principalmente se tende a impedir a realização de uma conduta instintiva ou, em última instância, ameace a sua sobrevivência. E, o comportamento de apego, por ter a função de regular a segurança do próprio indivíduo, não cobre outras funções como, por exemplo, a do comportamento de posse, que é a de regular a provisão para o usufruto próprio e/ou da prole, e portanto igualmente necessário à sobrevivência. Além dessas razões importantíssimas, a notória questão da posse, presente na vida do homem e de outros animais, levou Elyseu Jr. (1996) a sugerir e, depois, postular uma teoria etológica da posse (Elyseu Jr., 1998), na qual é proposta a existência de alguns padrões de posse à semelhança do que foi feito em relação ao apego.

Em relação ao sentido de usufruir o ambiente, muitas espécies animais, dentre as quais a humana, desenvolveram comportamentos instintivos como o de luta pela posse ou em defesa do território, da fêmea ou do alimento. A essas formas comportamentais Elyseu Jr. (1998) deu o nome genérico de comportamento instintivo de posse pelo fato de que, na tradição etológica, sempre que diferentes formas de comportamento têm em comum a mesma conseqüência se costuma reunilas numa só categoria, rotulada conforme essa conseqüência (Bowlby, 1969).

O exposto está, portanto, de acordo com o fato de que a sobrevivência animal está estruturada, basicamente, em dois sentidos: o de defender-se do ambiente, sobretudo da predação, e o de usufruir dele, servindose do que já está disponível ou tendo que obter aquilo que ainda não está, o que implica competições tanto intra, quanto interespecíficas (Elyseu Jr., 2006).

A figura de posse ( $f d p$ ) é definida como aquela que possui características para serem usufruídas pelo indivíduo e/ou pela sua prole, de modo imediato ou oportuno, e em virtude da qual o comportamento de posse se manifesta. No entanto, entende-se como necessária uma distinção entre tipos gerais de figura de posse, a 
saber: pessoas e animais - e - objetos e demais bens, por causa da distinção que pode ser feita entre interação e relação, pois geralmente o indivíduo interage com outras pessoas e animais, mas apenas se relaciona com coisas; por exemplo, um indivíduo pode ameaçar o outro de abandono o que um objeto não faz (Elyseu Jr., 2006).

Outra distinção, entre as figuras de apego e de posse, também é necessária. Nas espécies animais mais evoluídas, os filhos usufruem dos pais (figuras de posse), que realizam a sua alimentação, a sua defesa individual etc., enquanto não conseguem realizá-las por si mesmos. Esses comportamentos de alimentar e de proteger os filhos constituem parte do comportamento de cuidar dos pais; no entanto, apenas quando protegem os filhos das ameaças ambientais é que eles se constituem em figuras de apego. Uma figura de apego pode, portanto, ser uma figura de posse, embora o contrário não seja necessariamente verdadeiro. E, o filho só pode manifestar um comportamento de apego porque tem a posse de uma figura de apego, caso contrário, ele tem antes que obtê-la através do comportamento de posse.

Posse, vivência de posse e padrão de posse psicológica são conceitos diferentes. A posse é uma tendência ou disposição instintiva (filogenética) em obter e/ou manter figuras de posse, isto é, em ter o domínio sobre elas. Essa disposição é um atributo do indivíduo que parece não ser afetado pela idade, na medida em que figuras de posse são permanentemente essenciais à saúde física e psíquica ou até mesmo à sobrevivência, seja em relação ao alimento, seja em relação à proteção (abrigo etc.), seja em relação à afeição (conforto). A vivência de posse é um fenômeno cognitivoemocional de ter um relativo ou absoluto domínio sobre a figura de posse.

Entende-se que a qualidade predominante das vivências de posse do indivíduo contribua para a configuração do tipo de padrão de posse mais evidente nas suas relações interpessoais, com animais de estimação e no trato de seus bens materiais (Elyseu Jr., 1998, 2006). Ele é a forma organizada em virtude da qual a pessoa sente, pensa, deseja e se comporta sempre da mesma maneira em relação às suas figuras de posse (fenômeno homeorético).

Nesse sentido defende-se que, se no início da vida predominarem vivências de domínio ou controle sobre as principais figuras de posse (pai, mãe, avós, babás, animais de estimação, brinquedos, ambiente físico, etc), se estruturará um padrão de posse segura, ca- racterizado pela confiança do indivíduo de que suas figuras de posse não vão abandoná-lo (caso de pessoas), nem de que elas lhe serão tiradas ou perdidas, não precisando vigiá-las ou controlá-las etc. Por exemplo: um rapaz não vigia a namorada, que transita pela festa, por confiar nela.

Se a vivência for predominantemente a de ameaça de perda da figura de posse, feita por ela mesma ou por outra pessoa ou, ainda, porque o indivíduo já foi privado dela, supõe-se que se estruturará um padrão de posse ansiosa, caracterizado pela desconfiança e ansiedade de perda da figura de posse, precisando vigiá-la ou controlá-la e, no caso de objeto, escondêlo, não emprestá-lo etc. Por exemplo: alguém não empresta seus CDs por receio de que não lhe sejam devolvidos.

Se a vivência for predominantemente a de ter um rival, dividindo ou tentando dividir o usufruto da figura de posse, supõe-se que se estruturará um padrão de posse ciumenta, caracterizado pelo ciúme e por condutas que visem a posse exclusiva da figura de posse, como por exemplo uma mulher que não aceita que o companheiro receba telefonemas de colegas mulheres.

E finalmente, se a vivência for predominantemente a de frustração e/ou privação e/ou perda de figuras de posse, supõe-se que se estruturará, como reação defensiva, um padrão de posse reativa, caracterizado pela intensificação do comportamento para obter e/ou manter a figura de posse, como é o caso, por exemplo, da pessoa que só acumula riqueza em vez de usufruíla. Porém, esse tipo de defesa não é a única resposta possível às vivências de frustração e/ou privação e/ou perda da posse; pode ocorrer alternativamente a desativação do comportamento de posse ou a ativação do comportamento invejoso, que podem estruturar padrões, mas não os de posse.

Os padrões acima podem ser pensados ainda do ponto de vista da segurança da posse. Conforme identificado por Elyseu Jr. (2006), a segurança constitui uma das dimensões da posse, cujo espectro vai desde as manifestações de posse segura propriamente dita (pólo positivo) até as manifestações de posse ansiosa e de posse ciumenta (pólo negativo).

Como a segurança da posse é semelhante à do apego, nova distinção deve ser feita. Na medida em que o apego é uma tendência de manter proximidade a uma figura com o fim de proteção, a segurança do apego significa que o indivíduo acredita que será protegido contra ataques ambientais, quando estiver junto dessa figura. E, sendo a posse uma tendência de exercer um 
domínio sobre uma figura para usufruto próprio e/ou da prole, a segurança da posse significa que o indivíduo acredita que detém esse domínio e, portanto, o usufruto dessa figura. Por exemplo: se a pessoa confia que seu companheiro(a) não vai traí-la(lo), interessando-se por outra pessoa, entende-se que apresenta segurança da posse em relação a ele(a); e, se confia que será protegida por outra mais forte que ela contra a agressão de terceiros, entende-se que apresenta segurança de apego. Ou ainda, uma criança pode sentir que seus brinquedos continuarão sendo seus, isto é, vivencia segurança de sua posse, mas nenhum deles, exceto o "ursinho", é capaz de fazê-la sentir-se protegida, quando vai dormir. Em outras palavras, apenas o "ursinho", dentre as suas figuras de posse, funciona como figura de apego e a faz vivenciar a segurança do apego.

Quer dizer, uma figura de posse pode ser usufruída de diversas maneiras por causa dos seus diferentes atributos, entre os quais o de dar proteção, concreta ou supostamente. Quando isso ocorre conclui-se que as figuras de posse e de apego se superpõem, e a vivência de segurança fica assim reforçada.

\section{Identificação dos padrões na clínica psicológica}

Feitas as distinções entre as figuras e os comportamentos de apego e de posse, e como eles podem se estruturar em diferentes padrões, cabe agora identificá-los no contexto psicoterápico para mostrar como eles se manifestam na comunicação transferencial de processos de psicoterapias psicodinâmicas. São relatados trechos de sessões terapêuticas conduzidas pelo primeiro autor, que obteve o consentimento formal dos pacientes para a sua divulgação. Ligeiras modificações para preservar o anonimato do paciente foram realizadas. O primeiro fragmento se refere a uma manifestação saudável de posse segura. $\mathrm{O}$ pai relata uma situação de sua filha:

P- Minha filha, apesar de ter também passado na Unicamp, vai fazer o curso na USP.

T-Percebo que está triste com a separação.

$P$-É, depois de tanto tempo morando juntos é difícil se separar. Mas, não devo barrá-la.

T- Separação não é necessariamente perda, não é? Por isso está conseguindo suportar a sua angústia.

$P$ - É, eu me lembro de quando fui para $X$ (cidade onde $o$ P. fez o curso universitário quando jovem), no começo eu não via a hora de chegar o final de semana para voltar para casa.... e meus pais também ficavam me esperando com ansiedade.... mas com o tempo a gente vai se entrosando com a turma e começa a espaçar as voltas para casa.... mas tudo bem...a gente se acostuma...

T- Acho que você já está se preparando para quando sua filha vier a se entrosar com a turma dela também, não é?

$P$ - Hum, hum .... é, acho que sim.

Examinando a comunicação do ponto de vista da transferência verifica-se que o terapeuta aponta, na primeira intervenção, o sentimento subjacente (tristeza), frente à perda iminente do convívio diário com a filha, uma figura de posse amada. Sentindo-se compreendido, o paciente expressa claramente a ansiedade de separação (é difícil se separar); e a defesa de antecipação (a filha precisa seguir o seu caminho), fechando o triângulo de conflito (sentimento/ansiedade/defesa) (Malan, 1979/1983).

O uso da antecipação (ou ensaio afetivo) permite ao paciente atenuar os efeitos do conflito, na medida em que ele pode considerar não apenas soluções alternativas realistas e antecipar reações emocionais para problemas futuros, "mas realmente experienciar a angústia futura ligando mentalmente as idéias angustiantes aos afetos” (Perry, 1991, p. 55). Efetivamente, verifica-se que, após a nova intervenção suportiva do terapeuta, o paciente é capaz de iniciar um processo de elaboração do conflito, fazendo a ponte entre o presente (perda de uma figura de posse) e situações semelhantes do passado, quando foi ele quem deixou a casa dos pais (figuras de apego e de posse). A situação bem resolvida do passado em que sair da casa dos pais não foi vivida como perdê-los para sempre (posse segura) ajuda-o agora a lidar com a situação da filha (parte do triângulo de pessoa), o que foi corretamente assinalado pelo terapeuta. Nesse caso a filha constituise uma figura de posse amada e não uma figura de apego porque o pai não a vê como fonte de proteção.

A seguir, a manifestação de posse ansiosa:

P- Briguei com o meu namorado porque ele não me ligou ontem à noite, como costuma fazer.

T- Você precisa da atenção do seu namorado para combater a sua sensação de que é sempre deixada para trás, ...como se sentia quando achava que sua mãe preferia o seu irmão...

$P$ - É, porque parece que ele não está mais se importando comigo.

T- Parece porque sente que todo mundo é igual à sua mãe... em vez de se apoiar nas demonstrações de interesse das pessoas ao seu redor. 
$P$ - É, ele vive dando atenção pra mim, mesmo quando eu não cobro.

Algumas sessões mais tarde, ela disse ao terapeuta que a situação havia se repetido, mas não tinha ficado tão insegura quanto antes e que conseguiu não brigar.

Sentindo-se frustrada na sua expectativa de controle sobre o namorado (figura de posse), que não agiu como ela desejava, a paciente brigou com ele. Dessa forma, deu expressão à defesa de acting out, caracterizada por comportamentos e atitudes "sem reflexão ou sem consideração aparente em relação às conseqüências negativas” (Perry, 1991, p. 5). O uso do acting out ocorre freqüentemente em relações interpessoais com pessoas significativas e envolve a expressão de sentimentos sobre os quais a pessoa não tem nenhum controle.

A intervenção do terapeuta teve como finalidade apontar o sentido transferencial de sua fala ao relacioná-la a um padrão conflitivo recorrente, segundo o qual, na disputa pela posse da mãe, ela se sentia sempre preterida em relação ao irmão (padrão ansioso de posse). Com a segunda intervenção, o terapeuta busca apontar a diferença da situação infantil da atualmente vivida pela paciente, para ajudá-la a distinguir o presente do passado (triângulo de pessoas). E efetivamente, sua resposta parece refletir o reconhecimento de que o namorado costuma ter uma atitude diferente da mãe. E essa discriminação deve ajudá-la a mitigar o conflito primário, reeditado transferencialmente (Malan,1979/1983).

O terceiro exemplo se refere a uma manifestação de posse ciumenta:

P- Uma amiga me perguntou o seu nome porque pensava em fazer terapia, mas eu não falei.

$T$ - Você me valoriza tanto que não consegue me dividir com os outros e, talvez, nem passe pela sua cabeça que eu me relaciono com outras pessoas.

$P$ - De fato eu não penso nisso.

$T$ - Creio que você nunca sentiu ter completamente a posse de alguém.

$P$ - É, acho que isso nunca aconteceu.

T- Talvez porque dividir signifique para você perder completamente.

$P$ - Pode ser.

Na comunicação transferencial fica clara a ansiedade frente à possibilidade de divisão de usufruto do objeto com outra pessoa, já que se deseja a sua posse exclusiva (ciúme). Verifica-se aí o emprego de identificação projetiva, suscitada pela experiência emocional de que a outra pessoa a estaria ameaçando, e pela qual o sujeito "reage ao ataque imaginário (ou parcialmente real), atacando e acreditando que suas ações são justificadas, apesar de estar realmente provocando o outro" (Perry, 1991, p. 18). A ação de sonegar a informação (o nome do psicólogo) foi portanto uma reposta à ansiedade despertada pela vivência de que poderia perder a posse do terapeuta ao compartilhá-lo com outra pessoa.

As intervenções evoluíram de uma compreensão empática do ciúme apresentado para uma explicação possível da sua existência e do seu sentido para a paciente, que também não considera o acontecimento em termos relativos (dividir, para ela, significa perder completamente a figura de posse). Fica ainda evidente a natureza transferencial do padrão de posse, que se reedita no aqui e agora, na figura do terapeuta. $\mathrm{Na}$ sessão seguinte, a paciente disse a ele que tinha dado o seu nome à amiga, mas conforme intuído pelo terapeuta e posteriormente verificado com a continuidade do processo tratava-se de uma defesa só para que ele não viesse a desgostar dela e não uma autêntica mudança quanto ao seu ciúme.

O último exemplo refere-se a uma manifestação de posse reativa:

P- Eu sempre tenho que comprar as coisas em dobro. Uso uma e a outra fica guardada.

T- Gostaria de ter um clone de mim guardado no seu armário?

$P$ - (Deu risada)

T- Acha que com coisas guardadas está protegido...

P- Protegido não... garantido.

$T$ - É, garantido contra a ameaça explícita nas palavras de sua mãe. (A mãe, embora desejasse que os filhos usufruíssem as coisas, sempre acenava com a possibilidade de não poderem continuar desfrutando delas no futuro)

$P$ - Eu sei, mas parece que ela tem razão.

$T$ - Mesmo que, durante esses anos todos, isso nunca tenha se confirmado?

$P$ - É.

T- Você tem medo de discordar da sua mãe. Parece que você teme que, quando isso acontece, ela acha que você não gosta dela?

$P$ - É. 
T- De modo que você virou um escravo das idéias dela ou do que ela deseja?

A guarda da duplicata, identificada como figura de posse e não como de apego, caracteriza a posse reativa como defesa à possibilidade de ficar sem nada (ansiedade de desprovisão). No caso, não foi a vivência da falta de provisão que, em geral, leva a esse tipo de posse (por intensificação do comportamento de posse), mas sim a ameaça de desprovisão contida nas palavras da mãe.

Essa atitude reflete a ação do mecanismo de racionalização, segundo a qual o sujeito oferece uma razão aparentemente plausível para suas ações, quando um motivo que é mais de interesse pessoal ou de difícil reconhecimento está evidente para o observador. Essa defesa protege a pessoa do sentimento de vergonha e de embaraço, que a consciência da origem de seus atos poderia lhe trazer (Perry, 1991).

As intervenções do terapeuta no sentido de confrontar a fartura real e a expectativa de ficar sem nada e, principalmente, o questionamento da falta de direito de discordar da mãe, mesmo que ela sofra, propiciaram ao paciente condições para elaborar e evoluir terapeuticamente. Depois de algum tempo, o paciente disse ter comprado e usado, pela primeira vez, um par de tênis sem duplicata para garantia. Diga-se, porém, que isso coincidiu com o ganho de seu primeiro salário como profissional. É possível que a sensação do poder aquisitivo pessoal também tenha contribuído para a mudança do padrão de posse reativa.

Como as manifestações dos padrões de apego já são bastante conhecidas, optou-se por apresentar apenas o fragmento de caso clínico relativo ao padrão de apego ansioso, o qual pode ser manifesto na relação transferencial com o terapeuta na medida em que esse se constitui numa figura de apego para o paciente, como observado a seguir:

P- Senti muita falta do nosso encontro (o dia da sessão coincidiu com um feriado).

T- Você só se sente seguro quando está aqui?

$P$ - Não é bem assim, mas me sinto mais seguro quando estou aqui.

T- Tem a impressão de que a força está nos outros.

$P$ - Isso seria cômico, se não fosse trágico.

T- Pode deixar de ser trágico se você conseguir sentir a sua própria capacidade.

$P$ - Eu sei, mas não sinto.
T- Você acha que os outros já nasceram grandes e fortes?

$P$ - (Sorriu)

Passagens como essa repetiram-se ao longo da terapia, mas a mudança do padrão de apego ansioso não foi significante; o máximo conseguido parece ter sido uma pequena diminuição da ansiedade de separação, baseada no relato de que não sentiu muita falta de estar com o terapeuta quando, novamente, não houve sessão.

Por entender que o apego ansioso é estruturado por frustrações do comportamento de apego nos anos de imaturidade (infância e adolescência), Bowlby (1988/ 1989) preconiza que o terapeuta deve se constituir em uma figura de apego disponível e receptiva para o paciente. Uma base segura que oferece suporte para que ele possa explorar e enfrentar os aspectos dolorosos de sua vida, reavaliando-os e reestruturando-os segundo uma nova compreensão. Isto é, reconstruindo os modelos funcionais de si e dos outros mais adaptados à realidade.

Os autores, por sua vez, consideram que a avaliação do apego e da posse nas relações interpessoais fornece as bases para a compreensão das vivências afetivas dominantes, das ansiedades e das defesas que se atualizam na transferência, de sorte que ela pode ser muito útil para se compreender a dinâmica que se estabelece entre o paciente e o terapeuta, e orientar as intervenções desse último. Não se deve, no entanto, negligenciar as contribuições de outros autores que também subsidiam as ações que buscam atingir as metas psicoterápicas.

\section{CONSIDERAÇÕES FINAIS}

O presente trabalho procura não apenas reafirmar a importância e a aplicabilidade da Teoria do Apego no contexto psicoterápico, mas também mostrar que algumas manifestações clínicas são mais bem compreendidas pela recém-postulada Teoria da Posse, ressaltando com isso o valor na construção de teorias complementares para a compreensão psicológica humana. Pode-se observar ainda o paralelismo conceitual de ambas, mesmo porque estão baseadas em condutas instintivas, e a possibilidade de superposição das figuras de apego e de posse quanto à dimensão psicológica de segurança, embora as dimensões da posse não se restrinjam a ela. Por último, a compreensão das manifestações de posse do paciente permite ao psicoterapeuta a ampliação do manejo clínico, possibilitando 
uma intervenção mais abrangente da sua personalidade e, provavelmente, com melhores resultados.

\section{REFERÊNCIAS}

Ainsworth, M. D. S. (1963). The development of infant-mother interaction among the Ganda. Em M. F. Foss (Org.), Determinants of infant behaviour: Vol. 2. London: Methuen.

Ainsworth, M. D. S., Blehar, M. C., Waters, E., \& Wall, S. (1978). Patterns of attachment: a psychological study of the strange situation. Hillsdale, NJ: Erlbaum.

Bowlby, J. (1960). Separation anxiety. International Journal of Psycho-Analysis, 41, 89-113.

Bowlby, J. (1965). Child care and the growth of love. Baltimore: Penguin Books.

Bowlby, J. (1969). Attachment and loss: Vol. I. Attachment. New York: Basic Books.

Bowlby, J. (1973). Attachment and loss: Vol. II. Separation Anxiety and anger. London: Penguin Books.

Bowlby, J. (1979). The making and breaking of affectional bonds. London: Tavistock Publications.

Bowlby, J. (1989). Uma base segura: Aplicações clínicas da teoria do apego. (S. M. de Barros, Trad.) Porto Alegre: Artes Médicas. (Original publicado em 1988)

Bowlby, J. (1990). Apego (2a ed.) (A. Cabral, Trad.). São Paulo: Martins Fontes.

Bretherton, I. (1980). Young children in stressful situations: The supporting role of attachment figures and unfamiliar caregivers.
Em G. V. Coelho \& P. J. Ahmen (Orgs.), Uprooting and development (p.179-210). New York: Plenum Press.

Elyseu Jr., S. (1996). Contribuições a uma teoria de personalidade. Campinas: Alínea.

Elyseu Jr., S. (1998). Teoria da posse. Estudos de Psicologia, 15(1), 77-80.

Elyseu Jr., S. (2006). Construção e validação de Escala de Posse. Tese de Doutorado não publicada, Pontifícia Universidade Católica de Campinas, SP.

Fonagy, P. (1999). Persistencias transgeneracionales del apego: Una nueva teoría (M. de Iceta, Trad.). Manuscrito não publicado.

Malan, D. H. (1983). Psicoterapia individual e a ciência da psicodinâmica (M. C. Juchem, Trad.). Porto Alegre: Artes Médicas. (Original publicado em 1979)

Perry, J. C. (1991). Escalas de avaliação dos mecanismos de defesa ( $5^{\mathrm{a}}$ ed.) (D. Wiethaeuper e E. M. P. Yoshida, Trad.). Manuscrito não publicado.

Yoshida, E. M. P., \& Rocha, G. M. A. (2007). Avaliação em psicoterapia psicodinâmica. Em J. C. Alchieri (Org.), Avaliação psicológica: Perspectivas e contextos (p. 237-280). São Paulo: Vetor.

Recebido: 06/06/2006

Revisado: 29/11/2006

Aceito: 20/12/2006

\section{Sobre os autores:}

Sebastião Elyseu Júnior: Professor de Teorias Psicanalíticas I e II e Supervisor de Estágio Supervisionado em Psicologia da Saúde/Clínica II da Faculdade de Psicologia - Pontifícia Universidade Católica de Campinas.

Elisa Medici Pizão Yoshida: Professora de Estágio Supervisionado em Psicologia da Saúde/Clínica II da Faculdade de Psicologia e Orientadora do Programa de Pós-graduação em Psicologia: Profissão e Ciência - Pontifícia Universidade Católica de Campinas.

Endereço eletrônico: elyseu@directnet.com.br 